\title{
Exome sequencing in clinical settings: preferences and experiences of parents of children with rare diseases (SEQUAPRE study)
}

\author{
Aline Chassagne ${ }^{1,2,3}$ - Aurore Pélissier ${ }^{3,4}$ - Françoise Houdayer ${ }^{5}$. Elodie Cretin ${ }^{2,3}$ - Elodie Gautier ${ }^{6}$. \\ Dominique Salvi $^{5}$ - Sarah Kidri ${ }^{5}$ - Aurélie Godard ${ }^{1,2}$. Christel Thauvin-Robinet ${ }^{3,6}$ - Alice Masurel $^{6}$. \\ Daphné Lehalle $\mathbb{1}^{6} \cdot$ Nolwenn Jean-Marçais ${ }^{6} \cdot$ Julien Thevenon $\mathbb{1}^{6} \cdot$ Gaetan Lesca $^{5} \cdot$ Audrey Putoux $^{5}$. \\ Marie-Pierre Cordier $^{5}$. Sophie Dupuis-Girod ${ }^{5}$ - Marianne Till ${ }^{5}$ - Yannis Duffourd ${ }^{3}$ - Jean-Baptiste Rivière ${ }^{3}$. \\ Lorraine Joly $^{6}$. Christine Juif ${ }^{6} \cdot$ Olivier Putois $^{7} \cdot$ Pierre Ancet $^{8} \cdot$ Anne-Sophie Lapointe $^{9} \cdot$ Paulette Morin $^{9}$. \\ Patrick Edery ${ }^{5}$ Massimiliano Rossi ${ }^{5}$ - Damien Sanlaville ${ }^{5}$. Sophie Béjean ${ }^{4}$. Christine Peyron ${ }^{4} \cdot$ Laurence Faivre $^{3,6}$
}

Received: 10 October 2017 / Revised: 28 November 2018 / Accepted: 11 December 2018 / Published online: 1 February 2019

(c) European Society of Human Genetics 2019

\begin{abstract}
Exome sequencing (ES) has revolutionized diagnostic procedures in medical genetics, particularly for developmental diseases. The variety and complexity of the information produced has raised issues regarding its use in a clinical setting. Of particular interest are patients' expectations regarding the information disclosed, the accompaniment provided, and the value patients place on these. To explore these issues in parents of children with developmental disorders and no diagnosis with known etiology, a multidisciplinary group of researchers from social and behavioral sciences and patient organizations conducted a mixed-methodology study (quantitative and qualitative) in two centers of expertise for rare diseases in France. The quantitative study aimed to determine the preferences of 513 parents regarding the disclosure of ES results. It showed that parents wished to have exhaustive information, including variants of unknown significance possibly linked to their child's disorder and secondary findings. This desire for information could be a strategy to maximize the chances of obtaining a diagnosis. The qualitative study aimed to understand the expectations and reactions of 57 parents interviewed just after the return of ES results. In-depth analysis showed that parents had ambivalent feelings about the findings whatever the results returned. The contrasting results from these studies raise questions about the value of the information provided and parents' high expectations regarding the results. The nature of parental expectations has emerged as an important topic in efforts to optimize accompaniment and support for families during the informed decision-making process and after disclosure of the results in an overall context of uncertainty.
\end{abstract}

These authors contributed equally: Aline Chassagne, Aurore Pélissier, Françoise Houdayer

These authors jointly supervised this work: Christine Peyron, Laurence Faivre

Supplementary information The online version of this article (https:// doi.org/10.1038/s41431-018-0332-y) contains supplementary material, which is available to authorized users.

Laurence Faivre

laurence.faivre@chu-dijon.fr

Extended author information available on the last page of the article

\section{Introduction}

With the dramatic fall in the cost of exome sequencing (ES) and its high diagnostic yield, ES is about to become a firstline diagnostic procedure in routine practice in numerous fields of genomic medicine, particularly for developmental disorders (DD) [1]. With previous diagnostic strategies, involving a combination of cytogenetic and metabolic methods as well as targeted gene sequencing, it was possible to identify the genetic causes of a disease in around $20-30 \%$ of patients with undiagnosed DD [2]. The diagnostic yield of ES ranges from $25 \%$ to $50 \%$ [3], and can reach even $60 \%$ for genome sequencing (GS) [4] in undiagnosed cases. ES provides a real opportunity to end diagnostic odysseys, and would thus have a positive impact for patients and their relatives in terms of family planning, 
care trajectories, and psychological and emotional wellbeing [5].

Nonetheless, the implementation of these tests in clinical settings raises ethical and societal issues related to the complexity of the information to disclose to patients before the diagnostic test and afterwards, when the results are returned [6-9]. EuroGentest and the European Society of Human Genetics have proposed guidelines and recommendations for good practices for the implementation of ES and the expression of informed consent [10, 11]. Social and behavioral research has mainly investigated the nature and the scope of the information to disclose, particularly with regard to variants of unknown significance (VUS) and secondary findings (SF). Studies on the point of view of patients, their parents/families, and health professionals have reported mainly favorable attitudes towards the genomic information ES can yield. Concerning SFs, most patients (or parents/families) would prefer the information to be made available, particularly when it concerns not only preventable or treatable diseases, but also incurable diseases [12-19]. Parents are also in favor of receiving information about VUS possibly linked to their child's disease [14, 19]. Nonetheless, with regard to the nature of the genetic information screened for and disclosed, the preferences of patients (or their parents/families) can differ from those of health professionals $[14,20-22]$. Patients generally favor the return of exhaustive results whereas health professionals prefer the disclosure of selected information. Furthermore, health professionals often emphasize strict clinical utility while patients value a more personal and multidimensional utility. Middleton et al. [23] showed that even health professionals had different opinions about the return of SF, with genetic healthcare professionals being more conservative than non-genetic health professionals and genomic researchers. Though no consensus has emerged from the literature, studies investigating patients and their families showed that they wished to be involved in the decision to choose the categories of results returned [10, 14, 17]. In this context, it is important to assess individual preferences and to understand the experiences and attitudes of patients and families regarding the results of ES. While the literature mainly focuses on hypothetical preferences, few studies have attempted to understand the experience of parents in real-life situations following the return of diagnostic test results and the psychosocial effects of such disclosures in the field of rare diseases $[24,25]$. Several studies have focused on how to deal with the uncertainty inherent in these tests [26-28].

The aim of our study was to answer questions raised by the transfer of ES from research to care in France, the ultimate goal being to develop an approach centered on the needs and the wishes of the patient. Given the results reported in the literature, it seemed appropriate to investigate patient expectations throughout the process of ES testing: their preferences before the test (what kind of information do they value? how do they want to be supported in the decision-making process?), while waiting for the results (do they want support during the waiting period?), their experience after the disclosure of the test results (what are their feelings about the results delivered? how do they compare with their expectations?).

These expectations should be taken, into account in order to deepen our knowledge about the information and support that should be provided to patients throughout the ES process. This study could contribute to the preparation of recommendations applicable to the clinical practice of healthcare professionals in French genetics centers. It may also add new knowledge and empirical evidence to the international literature on patient preferences and experiences as regards ES.

\section{Materials and methods}

This study focuses on the preferences and experiences of parents of children with undiagnosed DD with regard to the nature of the genomic data screened for and disclosed, and the support provided to the patient both before (pre-ES) and after (post-ES) the test. We used a mixed methodology: a quantitative and a qualitative study were carried out simultaneously (Fig. 1). The quantitative study focused on the pre-test phase, during which hypothetical preferences were determined in a large sample of respondents. The qualitative study focused on expectations, reactions and preferences during the post-test phase. As this phase aimed to understand attitudes and emotions an in-depth approach was required, and, therefore, a smaller number of respondents were recruited. Given the specific aim and methodological requirements of each study, different samples of parents were used. The overall project was supervised by a multidisciplinary team, assembled for the project, and composed of researchers in social and behavioral sciences, hospital practitioners and healthcare professionals working in genetics centers, as well as representatives from support groups for patients with rare diseases. The overall study was approved by the Ethics Committee of Dijon University Hospital.

\section{Prior preferences of parents with regard to ES-the quantitative study}

A discrete choice experiment (DCE) was used to determine the preferences of parents with regard to the disclosure of ES results. The methodology is detailed in the Supplementary Material. 


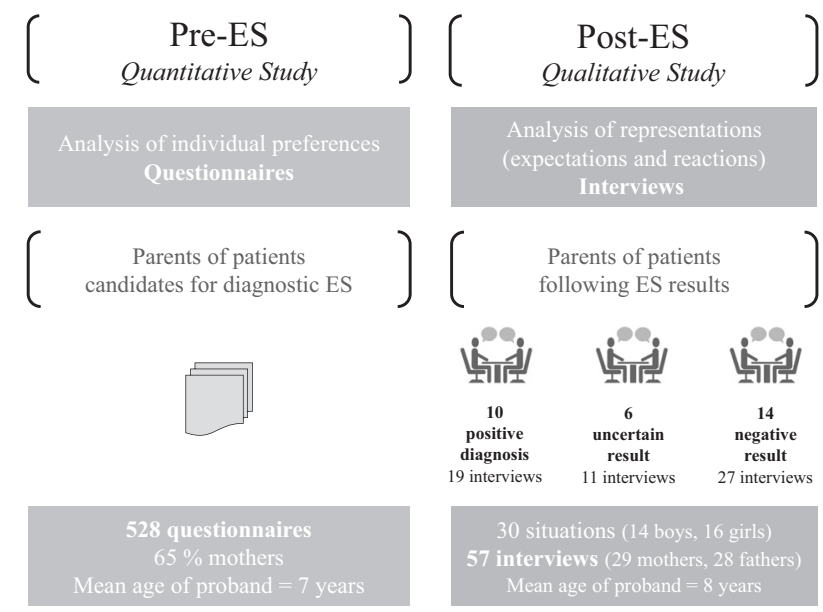

Fig. 1 Design of the study. The quantitative phase and the qualitative phase are presented with their respective sample of patients

In economics, preferences drive the decision-making process inherent to any choice made by an individual. Here, we were interested in choices related to the disclosure of ES results. Several configurations regarding the nature of the results and the way to disclose them was suggested to the parents. We wanted to understand what criteria most closely matched their expectations. A DCE makes it possible to study these hypothetical preferences through the analysis of a set of successive choices made by a sample of respondents between different configurations for disclosure of the ES results. To define the configurations, we retained six criteria (Table 1): (1) disclosure of VUS (none, only the most likely, or all); (2) disclosure of SF (no SF, only actionable $\mathrm{SF}$, or all); (3) possibility to reanalyze the test (never, automatically every year, or at the request of the respondent); (4) person who chooses the type of results that should be disclosed (the respondent, the geneticist, or an ethics committee); (5) type of support provided while waiting for the results (appointment with a nurse, a psychologist, the geneticist, or a meeting with other families); (6) out-ofpocket payment ( $€ 1$, €300, €600, or $€ 900$ ). We included 513 parents of children with undiagnosed DD who would be eligible for ES if it were proposed in a diagnostic setting. They had to make six successive choices between two different configurations of a test (combining the six predefined criteria) called "Test A" and "Test B" (Fig. 2). In so doing, respondents had to compare Test $\mathrm{A}$ and $\mathrm{B}$ and choose the one they globally preferred. Such tradeoffs provided information about their preferences. The six successive choices were analyzed through a conditional logit model that determined to what extent each criterion that defined the configuration of the test did or did not influence the choice of respondents (measured by the probability of choosing the test), i.e. their preferences. More precisely, if the estimated coefficient for one criterion was statistically significant (at least 5\%) and positive (or negative), it implied that the criterion increased (or decreased) the probability of choosing the test. If the coefficient was not significant, the criterion did not influence the probability of choosing the test.

The data were collected between February and December 2015 by two interviewers trained in the DCE approach and in conducting interviews. Oral consent was obtained from the respondents before starting the interview, which lasted from 20 to $30 \mathrm{~min}$. There were also questions about the respondents' perception of the survey, their knowledge about genetics, and certain socio-economic characteristics. Because the respondents may not have been familiar with the DCE questionnaire, the interviewers took time to present and explain the items and their values.

\section{Post-ES experience of parents-the qualitative study}

The aim was to understand and to obtain in-depth descriptions of the expectations and reactions of parents concerning the return of the results. At the end of a routine consultation, the geneticist presented the study to the parents. Volunteer participants were consecutively included until the planned sample size was reached. We had planned to collect data from 30 cases [29]. The sample was divided into three groups according to the three categories of possible scenarios: (1) Group 1: positive result (a genetic diagnosis was made, with the identification of a disease-causing variant associated with a known disease: $n=10$ situations and 19 interviews); (2) Group 2: uncertain result (VUS) (a VUS potentially compatible with the phenotype was detected, the characteristics of the variant or the clinical evidence being insufficient to make a diagnosis: $n=$ 6 situations and 11 interviews); (3) Group 3: negative result, no diagnosis could be made $(n=14$ situations and 27 interviews) (Fig. 1).

Individual, semi-structured, face-to-face interviews were conducted with the parents of children with DD who had undergone ES. Interview guides were developed by the multidisciplinary team. The interviews generally started with an open question such as "Tell me, how did the consultation go?" to encourage the exchange. Four main themes were successively explored: (1) The parents' expectations: "What were your expectations before the test was done?"; (2) Understanding the procedure of the test and the result: "At what moment during the care trajectory was ES proposed to you?", "Can you tell me about your result?"; (3) Understanding the experience of the return of the results: "How did you react?"; (4) The expected repercussions of the result and the anticipation of the future follow-up: "Will this result lead to modifications in your child's care?", "Will this result modify your child's daily life?"; and if the exam 
Table 1 Discrete choice experiment: attributes and their levels

\begin{tabular}{|c|c|c|}
\hline Criteria & Description & Value of the criteria \\
\hline Variants of unknown significance & $\begin{array}{l}\text { Disclose to parents genetic mutations related to the disease for which } \\
\text { the test was prescribed, but for which the geneticist only has } \\
\text { presumptions }\end{array}$ & $\begin{array}{l}\text { None } \\
\text { Only the most probable factors } \\
\text { All }\end{array}$ \\
\hline Secondary findings & $\begin{array}{l}\text { Disclose to parents genetic mutations which cause or may be found to } \\
\text { cause other diseases than the one for which the test was prescribed }\end{array}$ & $\begin{array}{l}\text { None } \\
\text { Possibly actionable (curative } \\
\text { and/or preventive) } \\
\text { All }\end{array}$ \\
\hline Reanalysis in the future & $\begin{array}{l}\text { Possibility to reanalyze the test data because of possible } \\
\text { modifications of the results (certain, uncertain, incidental) with the } \\
\text { evolution of medical knowledge }\end{array}$ & $\begin{array}{l}\text { Never } \\
\text { Automatically every year } \\
\text { On my request }\end{array}$ \\
\hline $\begin{array}{l}\text { Persons choosing the type of results } \\
\text { that should be given back }\end{array}$ & $\begin{array}{l}\text { Identity of the person who decides whether or not to disclose } \\
\text { uncertain and/or incidental results }\end{array}$ & $\begin{array}{l}\text { Me alone } \\
\text { My geneticist } \\
\text { An ethics committee }\end{array}$ \\
\hline $\begin{array}{l}\text { Type of accompaniment while waiting } \\
\text { for the results }\end{array}$ & $\begin{array}{l}\text { Accompaniment which could be proposed to patients while waiting } \\
\text { for the results }\end{array}$ & $\begin{array}{l}\text { Appointment with the geneticist } \\
\text { Appointment with the } \\
\text { psychologist } \\
\text { Appointment with the nurse } \\
\text { Meetings with other families }\end{array}$ \\
\hline Out-of-pocket payments & $\begin{array}{l}\text { Cost to patient: to determine the sensitivity of families to a } \\
\text { hypothetical payment }\end{array}$ & $€ 1, € 300, € 600, € 900$ \\
\hline
\end{tabular}

Note: Secondary findings were presented to the respondents in the following way by the interviewer: "The examination may reveal genetic variants that cause or could cause in the future other illnesses than the health problems you came for. These illnesses could concern your children, you, or even other members of your family"

\begin{tabular}{|c|c|c|}
\hline & \multicolumn{2}{|c|}{ CHOICE $\mathrm{N}^{\circ} 1$} \\
\hline & TEST A & TEST B \\
\hline Variants of unknown significance & None & All \\
\hline Incidental findings & Possible action & None \\
\hline Reanalysis in the future & Never & On my request \\
\hline $\begin{array}{l}\text { Persons choosing the type of } \\
\text { results that should be given back }\end{array}$ & Ethics committee & My geneticist \\
\hline $\begin{array}{l}\text { Type of accompaniment while } \\
\text { waiting for the results }\end{array}$ & Appointment geneticist & Meetings with other families \\
\hline Willingness to pay & 600 euros & 900 euros \\
\hline \multirow[t]{3}{*}{ I choose test (tick) } & $\mathrm{X}$ & \\
\hline & \multicolumn{2}{|c|}{ CHOICE N² } \\
\hline & TEST A & TEST B \\
\hline Variants of unknown significance & The most likely & None \\
\hline Secondary findings & All & Possible action \\
\hline Reanalysis in the future & On my request & Automatically \\
\hline $\begin{array}{l}\text { Persons choosing the type of } \\
\text { results that should be given back }\end{array}$ & Ethics committee & My geneticist \\
\hline $\begin{array}{l}\text { Type of accompaniment while } \\
\text { waiting for the results }\end{array}$ & Appointment psychologist & Meetings with other families \\
\hline Willingness to pay & 1 euro & 300 euros \\
\hline I choose test (tick) & & $\mathrm{X}$ \\
\hline
\end{tabular}

Fig. 2 Two examples of choices presented to the respondents in the discrete choice experiment (quantitative study). Reading: In this example, the respondent has chosen Test A in the first choice and Test $\mathrm{B}$ in the second choice. According to the theory of economics and given the configurations of the tests presented, Test A is globally preferred to Test B in choice 1 and in choice 2 it is the opposite. Note that the configurations of Test $\mathrm{A}$ and Test $\mathrm{B}$ differ in choice 1 and choice 2. The respondents have to make tradeoffs between Test A and Test B in each choice. In total, each respondent made six choices

led to no result, "Would you be willing to do additional analyses in the future to obtain a diagnosis?".
In order to analyze the affective responses, the interviews took place immediately after the consultation during which the parents received the results. It was decided to see each parent separately to gather their individual views and emotions without the influence of the other parent. The interviews, conducted by a psychologist and two sociologists, were recorded and entirely transcribed. The interviews lasted from 13 to $65 \mathrm{~min}$, with an average of $38 \mathrm{~min}$. Written consent was obtained from all parents. To analyze the data, we used an inductive analysis by theme [30]. The methodology used to analyze the data are presented in depth in the Supplementary Material.

\section{Results}

\section{Prior preferences of parents with regard to ES-the quantitative study}

The main descriptive statistics for the respondents $(n=513)$ are presented in Table 2.

The conditional logit results showed that three items strongly influenced parent preferences (Fig. 3): the disclosure of VUS, the disclosure of SF, and the possibility of re-analyzing the test results. The other items (the decisionmaker, support, and out-of-pocket payments) played a marginal role in the parents' decision-making process. First, the parents preferred to have VUS, particularly the most probable, and SF, even for incurable diseases, to not having 
Table 2 Descriptive statistics of the parents interviewed

\begin{tabular}{|c|c|}
\hline Mean or percentage share & $N=513$ \\
\hline Median age of the parents interviewed (years) & 37.46 \\
\hline Median age of child (years) & 7.00 \\
\hline Household size & 3.97 \\
\hline Mother $(\%)$ & 64.91 \\
\hline Couple $(\%)$ & 85.55 \\
\hline \multicolumn{2}{|l|}{ Household income } \\
\hline$<€ 1500$ & 21.39 \\
\hline$[€ 1500-€ 2500[$ & 32.48 \\
\hline$[€ 2500-€ 3500[$ & 24.95 \\
\hline$[€ 3500-€ 5000[$ & 17.23 \\
\hline$\geq € 5000$ & 3.96 \\
\hline \multicolumn{2}{|l|}{ Educational level } \\
\hline No schooling/primary school & 2.37 \\
\hline Middle school/completed middle school & 5.33 \\
\hline Vocational certificate & 29.59 \\
\hline High school diploma & 21.89 \\
\hline $2 / 3$ years higher education & 29.59 \\
\hline 5 years and more in higher education & 11.24 \\
\hline Pregnancy/plan to have child (\%) & 20.51 \\
\hline \multicolumn{2}{|l|}{ Knowledge of genetics (\%) } \\
\hline Very poor & 30.99 \\
\hline Poor & 33.53 \\
\hline Average & 25.93 \\
\hline Good & 7.41 \\
\hline Very good & 2.14 \\
\hline \multicolumn{2}{|c|}{ Number of genetic tests performed before WES was proposed (\%) } \\
\hline None & 32.94 \\
\hline $1-3$ & 51.76 \\
\hline $3-7$ & 10.00 \\
\hline $7-10$ & 2.55 \\
\hline More than 10 & 2.55 \\
\hline Time between survey date and first consultation (in years) & 1.30 \\
\hline
\end{tabular}

such results. Second, the possibility of continuing diagnostic investigations, particularly the annual automatic reanalysis of data, was also preferred. Third, the respondents preferred decisions about the disclosure of the results to be made by their geneticist rather than by themselves or by an ethics committee. Fourth, while waiting for the results, respondents preferred to be accompanied by the geneticist or a psychologist rather than by a nurse or to meet other families. Finally, the respondents were prepared to pay to have access to a diagnostic ES, up to a threshold estimated here at $€ 413$ (calculation method in Supplementary Material); above this threshold, the likelihood of choosing the test diminished.

\section{Post-ES experiences of parents-the qualitative study}

The sample, which was different from that in the quantitative study, included 30 parents of children with DD who had undergone ES (Fig. 1).

The characteristics of the sample are described in Table 3 .

The first theme explored was the expectations of the parents. For most parents, the main expectation was to "get a name for the disease" (especially for group 1 with a positive result) and to "find the origin of the disease": "We were really expecting a name for what she has, that's it. That is what motivated the research, to push the research a little further, to be able to have an answer" (mother, no. 1 04). The parents also mentioned a strong expectation to have more information to control the uncertain future: "So the goal is to know... finally to know... the name for it, to see what the future has in store" (father, no. 1-06). Parents spoke about their need to anticipate the future, and to be able to obtain information from other patients with the same diagnosis. The diagnosis was seen as a step towards adding knowledge about the evolution of the disease, improving genetic counseling and acting on care management. Several parents underlined the importance of contributing knowledge for the benefit of other families, or for science (especially group 3 with negative results). Parents rarely spoke about the possibility of SF.

The second theme explored parents' understanding of the test procedure and the result. For all of the parents interviewed, having this test done was not seen as a carefully thought out choice, but rather a way to improve their chances of obtaining a diagnosis thanks to a technical opportunity. Nonetheless, most of them had little information about the complete test procedure; they often believed that the test was simply a blood test: "we take a blood test and they look for..." (mother, no. 1-03) "We take a blood test and then we wait for the result. Whether it's lowthroughput sequencing, high-throughput sequencing, veryhigh-throughput sequencing, it doesn't actually have an impact. The impact is the result" (father, no. 1-05).

The third theme explored was the experience of the return of the results. Generally, the parents interviewed had difficulty understanding the genetic vocabulary (especially group 1). When they had been given a positive result, they always remembered the mode of transmission, most often de novo in our study. Parents often spoke of the result by referring to a "gene problem" (mother, no. 1-19), a "letterwriting problem" (mother, no. 1-03), or "genetic accident" (mother, no. 1-18). The question of the meaning of the result was raised by some parents: "the much talked about gene is called XXXX (the name of the gene), or something 


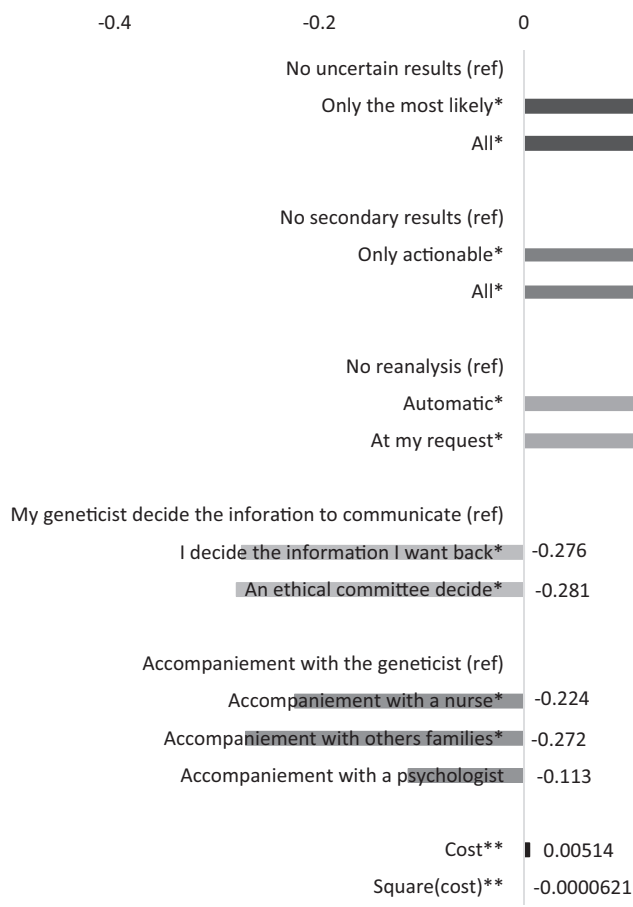

Fig. 3 Results of the quantitative study, showing the characteristics that influenced the probability that the respondent would choose an ES test. The estimation of coefficients is based on a conditional logit model with clustered standard errors at individual levels. $*$ and $* *$ indicate statistical significance of the coefficients at $1 \%$ and $5 \%$, respectively. (Ref.) indicates the reference level. The cost attributed was rescaled on a basis of 90 (rather than 900). Reading: for example, the positive coefficient $(0.859)$ associated with the "Only the most likely" value should be compared with the "Uncertain results" characteristic and interpreted as follows: the disclosure of the most likely

like that... It's what is responsible for the problem my daughter may have [...]" (father, no. 1-18).

During the interview, parents who obtained a diagnosis for their children very often expressed satisfaction (group 1, positive results). In their opinion, the diagnosis served a purpose of identification, of repair, of relief: "I'm glad I had this test done because it answered a number of questions" (mother, no. 2-04), "I feel happy and serene, less worried" (father, no. 1-07); "I'm pleased with the result; at last, we've been given a result today, because we've been waiting for 12 years. ....12 years is a long time. So, even if it's not... always great to hear, at last... I think it's going to take me some time to accept...the unacceptable" (mother, no. 1-01). A positive result could provide relief and put an end to the guilt often felt by some parents: "It is not our fault. I was really relieved because we did not transmit this genetic disease to my daughter. I was afraid I was carrying a gene and didn't know about it. And so, it was a great relief" (mother, no. 1-06). Some parents with VUS (group 2) were satisfied with the information provided: "We've never been so close", pointing out that "The geneticist won't give up" (father, no. 1-08). While other parents were disappointed uncertain results rather than no results (reference level) is preferred seeing as the coefficient for "Only the most likely" is statistically significant and positive. In other words, passing from "no uncertain results" to "only the most likely uncertain results" had a positive effect on the probability that the respondents would choose the test. When the coefficient is statistically significant and negative (for example, for support from a nurse), support from a nurse is less preferred than support from a geneticist (reference level) because it decreases the probability of choosing the test

with the inconclusive results: "We didn't get a result, we can't get a proper name for what my daughter... [silence] because for that he only gave me a letter followed by some numbers" (mother, no. 1-03). The parents of children with no result (group 3) were often disappointed, as one father said: "It's back to square one" (father, no. 1-15), and sometimes troubled: "It's really difficult to come in for a consultation and leave without something positive" (father, no. 2-06). Other parents expressed relief "For the moment, we still don't have any answers. [silence] It's long. [silence] but, whatever... I'm happy he's not sick. It's nothing serious" (mother, no. 1-02).

The fourth theme explored was the expected repercussions of the result and the anticipation of the future followup. For most parents, ES was a step "it's just the beginning" (mother, no. 1-18) towards another period of their life. "So, today we were given a name for what my daughter has, but it's the beginning, because I always said that it wasn't really important. It puts "a name" on what she has and anyway we are still worried about the future, that's it. I mean we still ask ourselves questions, today she's 5 years old... people who have the same thing, who are 15 years old, 20 years 
Table 3 Characteristics of the patients participating to the qualitative study

\begin{tabular}{|c|c|c|c|c|c|}
\hline Center/inclusion no. & Age (years) & Sex & Parents interviewed & $\begin{array}{l}\text { Number of children admitted } \\
\text { in specialized institution }\end{array}$ & WES result \\
\hline \multicolumn{6}{|l|}{ Center 1} \\
\hline $1-01$ & 12 & M & Mother and father & Yes & Positive (NR2F1 de novo variant) \\
\hline $1-02$ & 5 & M & Mother and father & No & Negative \\
\hline $1-03$ & 3 & $\mathrm{~F}$ & Mother & No & Uncertain (MSL3 de novo variant) \\
\hline $1-04$ & 20 & $\mathrm{~F}$ & Mother & Yes & Negative \\
\hline $1-05$ & 17 & $\mathrm{~F}$ & Mother and father & Yes & Positive (ADNP de novo variant) \\
\hline $1-06$ & 6 & $\mathrm{~F}$ & Mother and father & Yes & $\begin{array}{l}\text { Positive }(T B R I \text { de novo variant })+\text { secondary result } \\
\text { (BRCAl paternally inherited variant) }\end{array}$ \\
\hline $1-07$ & 15 & $\mathrm{~F}$ & Father & Yes & Positive (DYNClH1 de novo variant) \\
\hline $1-08$ & 0 & $\mathrm{M}$ & Mother and father & $\begin{array}{l}\text { No the child had died at the } \\
\text { time of the interviews }\end{array}$ & Uncertain (FAT4 compound heterozygous variant) \\
\hline $1-09$ & 6 & $\mathrm{~F}$ & Mother and father & No & Negative \\
\hline $1-10$ & 7 & M & Mother and father & No & $\begin{array}{l}\text { Uncertain ( } H D A C 10 \text { coumpound heterozygous } \\
\text { variant) }\end{array}$ \\
\hline $1-11$ & 6 & M & Mother and father & Yes & Positive (ASLXI de novo variant) \\
\hline $1-12$ & 5 & M & Mother and father & Yes & Negative \\
\hline $1-13$ & 5 & M & Mother and father & No & Negative \\
\hline $1-14$ & 19 & M & Mother and father & Yes & Negative \\
\hline $1-15$ & 3 & $\mathrm{~F}$ & Mother and father & No & Negative \\
\hline $1-16$ & 0,5 & $\mathrm{~F}$ & Mother and father & No & Positive (NSDI variant) \\
\hline $1-17$ & 16 & M & Mother and father & Yes & Uncertain (CHRNA7 de novo variant) \\
\hline $1-18$ & 5 & $\mathrm{~F}$ & Mother and father & No & Positive ( $D D X 3 X$ de novo variant) \\
\hline $1-19$ & 7 & M & Mother and father & Yes & Uncertain (MAB21L1 homozygous variant) \\
\hline $1-20$ & 6 & $\mathrm{~F}$ & Mother and father & Yes & Positive (DDX3X de novo variant) \\
\hline \multicolumn{6}{|l|}{ Center 2} \\
\hline $2-01$ & 13 & $\mathrm{~F}$ & Mother and father & No & Negative \\
\hline $2-02$ & 8 & M & Mother and father & No & Negative \\
\hline $2-03$ & 7 & M & Mother and father & No & Positive (ARIDIB variant) \\
\hline $2-04$ & 3 & $\mathrm{~F}$ & Mother and father & No & Positive ( $K M T 2 D$ variant) \\
\hline $2-05$ & 9 & $\mathrm{~F}$ & Mother and father & Yes & Negative \\
\hline $2-06$ & 6 & M & Mother and father & Yes & Negative \\
\hline $2-07$ & 14 & $\mathrm{~F}$ & Mother and father & No & Negative \\
\hline $2-08$ & 8 & $\mathrm{~F}$ & Mother and father & Yes & Negative \\
\hline $2-09$ & 2 & $\mathrm{~F}$ & Mother and father & No & Negative \\
\hline $2-10$ & 4 & M & Mother and father & No & Uncertain (PITX1 de novo variant) \\
\hline \multirow[t]{3}{*}{ Total } & $8^{\mathrm{a}}$ & 30 & 57 & 14 & 14 Negative results \\
\hline & & 16 girls & 29 Mothers & & 10 positive results \\
\hline & & 14 boys & 28 fathers & & 6 uncertain results \\
\hline
\end{tabular}

${ }^{\mathrm{a}}$ Mean

old, 25 years old, 35 years old or 40 years old etc., where, where do they stand, how does the disease evolve? Is there any progress today? Are there any techniques that allow people to improve their daily lives?" (father, no. 1-18). For half of group 1 (positive result), even when a diagnosis was made, a feeling of helplessness and uncertainty persisted. Improving care and daily life was a major concern for parents even though two-thirds of parents in group 1 (positive result) said that the result would not modify the care of their child or their way of life, and had not answered their questions about their worries for the future. For teenagers who had already been in institutions for several years, the expectations in terms of identification and social symbolism seemed less important to the parents. In uncertain cases and cases with no result, the parents wished to continue the diagnostic investigations. They expressed the wish to undergo additional analyses.

\section{Discussion}

We used both quantitative and qualitative approaches to examine the preferences and experiences of parents of children with DD regarding ES.

The quantitative study conducted with hypothetical scenarios revealed that parents preferred to be informed about VUS, especially the most likely ones, and about SF, even for incurable diseases. They also wanted test results to be 
reanalyzed, particularly if it was automatic, and to be involved in decision making. They also wished to be accompanied by a geneticist. The first two results showed that parents value exhaustive genomic information, beyond that for which the test was prescribed. The study reflected the fact that the parents of children with undiagnosed DD had a favorable attitude towards genomic information. This has also been underlined by other studies (qualitative or quantitative) that investigated patients or their family members who underwent ES for diagnostic purposes [12, 13, 15, 19, 31]. More broadly, positive attitudes towards genomic information were also found in other types of populations, such as cancer patients $[16,32]$ and even in the general population [33-35]. The fact that parents asked for exhaustive findings could be linked to the notion that access to results is considered a right [14, 15]. This desire for information can also be interpreted as prospective behavior, also reported in studies by Clift et al. [12] and Shahmirzadi et al. [19]. Indeed, our results suggested that the significant value is placed on the quantity of information. One could hypothesize that parents wished to maximize the chances of getting genomic information, whatever it may be, and thus improve their chances of obtaining a diagnosis. The preferences formulated by our respondents as regards an automatic yearly reanalysis reinforced this idea. This phenomenon could also be explained by the respondents' limited knowledge of genetics, even when they said they had a clear understanding of the notions of VUS and SF. A third explanation involves the notion of quality of life [12]. Knowing such information could help to alleviate uncertainty about the future and to prevent other diseases. Lastly, as mentioned by Sharmizadi et al. [19], this desire for information could reflect a low aversion to the disclosure of other genetic risks, given that these families already have to live with a genetic disease.

The qualitative study showed that parents had high expectations regarding the test. Beyond the new technical opportunity provided by the test, their main concern was to "get a name" for the child's clinical features. The parents who received a negative or uncertain result therefore continued to search for a diagnosis (and to undergo any new tests available) in order to get a name for the disease. Very often, "having a name" also meets a social expectation, as it allows parents to label their child's health condition, making it easier to explain it to their social circle [36], and to have better access to social support. Although such tests potentially provided positive or uncertain diagnostic information, this information did not necessarily meet parents' expectations as it did not always lead to improvements in care. In most cases, ES led to the diagnosis of ultra-rare diseases, for which there is very little information regarding the description of the disease, its course and possible interventions. Thus, our results showed that having a name was not enough. The diagnostic process should take into account the meaning and the implications of the diagnosis and patients and parents should be informed of these.

Most of the parents who had received at least some answers to their questions (Groups 1 and 2) expressed a feeling of relief. However, an in-depth analysis showed that the attitudes of parents were sometimes ambivalent. Indeed, the parents in all three scenarios experienced mixed feelings of both relief and worry, as also shown by the study of Krabbenborg et al. [24]. Some parents felt relieved when the result was negative. Even though they were hoping to obtain additional knowledge, they were also afraid of the information that might come with a diagnosis. This attitude could also be interpreted as a coping strategy to avoid disappointment.

The manner in which information was disclosed before and after ES was particularly important as it helped parents to avoid post-test disappointment or the persistence of a feeling of helplessness, whatever the result. The results opened up a new trajectory for which parents developed new expectations and difficulties. As a consequence, they needed more information [24, 37] and support in order to develop the coping skills they needed to live with continuing uncertainty [27, 28, 37, 38].

Comparison of the results from the two studies also raised questions about parents' expectations and the tangible impact of the result. The high and sometimes "unrealistic" expectations of parents regarding ES in terms of their child's trajectory have already been underlined in past work $[13,25,38]$. In the hypothetical scenario of the quantitative study, our results suggested that parents' strong interest in SF might be driven by the desire to reduce uncertainty. However, in the qualitative study, in the real-life situation, parents very rarely spoke spontaneously about SF. Their concerns were focused on other uncertainties: access to care, anticipation of the future, diagnosis, and the consequences of the illness [27]. ES might eliminate some uncertainties, but not all of them, and it tends to introduce new, additional uncertainties [28].

Several factors may have influenced the results of the study. The number of criteria investigated in the quantitative study was limited, and it may have been interesting to investigate other features (such as more precise categories of SF with variable penetrance and consequences). Moreover, given the use of a conditional logit, the potential heterogeneity of preferences could not be explored. The qualitative study was conducted just after the results were returned, and therefore did not reveal to what extent parents were able to come to terms with the results over time. Finally, given the sample studied, it is unlikely that the results can be generalized to other populations (such as cancer patients or the general population). 
The question of how patient preferences could be taken into account within a public healthcare system can be debated. In a health system like the French one, where resources are allocated according to need, and where access to care for all is an underlying principle, research and access to uncertain or secondary results will lead to greater expenditure on genetic tests for diagnostic purposes. Regulatory bodies may seek to control the costs and to define care protocols or conditions for the reimbursement of these tests. If access or reimbursement criteria were to be debated, it would lead to a negotiation based on the criterion of clinical utility, which would not necessarily be favorable to the search for any type of information. The criterion of social utility, which concerns the impact of genomic information on well-being, still needs to be clarified.

At a stage where France is starting to implement ES/GS in clinical practice for DD, our study showed that emphasis should be put on understanding, investigating, and revealing the real nature of parental expectations about genomic information throughout the ES process. Indeed, this should be done before the test to accompany the informed decisionmaking process, and after the test to support families after the results are returned, in an overall context of multidimensional uncertainty.

Acknowledgements The authors thank the Fondation Maladies Rares for its financial support of the study (APP Human and Social Sciences 2014) as well as the Conseil Régional de Bourgogne through the Plan d'Actions Régional pour l'Innovation (PARI 2015) and the European Union through the PO FEDER-FSE Bourgogne 2014/2020 programs. The authors also thank the parents who participated in the study.

\section{Compliance with ethical standards}

Conflict of interest The authors declare that they have no conflict of interest.

Publisher's note: Springer Nature remains neutral with regard to jurisdictional claims in published maps and institutional affiliations.

\section{References}

1. Iglesias A, Anyane-Yeboa K, Wynn J, et al. The usefulness of whole-exome sequencing in routine clinical practice. Genet Med. 2014;16:922-31.

2. Willemsen MH, Kleefstra T. Genetic diagnostics in intellectual disability: what is the benefit? Ned Tijdschr Geneeskd. 2014;158: A8098.

3. Yang Y, Muzny DM, Reid JG, et al. Clinical whole-exome sequencing for the diagnosis of mendelian disorders. N Engl $\mathbf{J}$ Med. 2013;369:1502-11.

4. Gilissen C, Hehir-Kwa JY, Thung DT, et al. Genome sequencing identifies major causes of severe intellectual disability. Nature. 2014;511:344-7.

5. Carmichael N, Tsipis J, Windmueller G, Mandel L, Estrella E. "Is it going to hurt?": the impact of the diagnostic odyssey on children and their families. J Genet Couns. 2015;24:325-35.
6. Berg JS, Khoury MJ, Evans JP. Deploying whole genome sequencing in clinical practice and public health: meeting the challenge one bin at a time. Genet Med. 2011;13:499-504.

7. Ormond KE, Wheeler MT, Hudgins L, et al. Challenges in the clinical application of whole-genome sequencing. Lancet. 2010;375:1749-51.

8. Pinxten W, Howard HC. Ethical issues raised by whole genome sequencing. Best Pract Res Clin Gastroenterol. 2014;28:269-79.

9. Borry P, Bentzen HB, Budin-Ljøsne I, et al. The challenges of the expanded availability of genomic information: an agenda-setting paper. J Community Genet. 2018;9:103-16.

10. Van ElCG, Cornel MC, Borry P, et al. Whole-genome sequencing in health care: recommendations of the European Society of Human Genetics. Eur J Hum Genet. 2013;21:580-4.

11. Matthijs G, Souche E, Alders M, et al. Guidelines for diagnostic next-generation sequencing. Eur J Hum Genet. 2016;24:2-5.

12. Clift KE, Halverson CME, Fiksdal AS, Kumbamu A, Sharp RR, McCormick JB. Patients' views on incidental findings from clinical exome sequencing. Appl Transl Genomics. 2015;4:38-43.

13. Facio FM, Eidem H, Fisher T, et al. Intentions to receive individual results from whole-genome sequencing among participants in the ClinSeq study. Eur J Hum Genet. 2013;21:261-5.

14. Fernandez CV, Bouffet E, Malkin D, et al. Attitudes of parents toward the return of targeted and incidental genomic research findings in children. Genet Med. 2014;16:633-40.

15. Fernandez CV, O'Connell C, Ferguson, et al. Stability of attitudes to the ethical issues raised by the return of incidental genomic research findings in children: a follow-up study. Public Health Genomics. 2015;18:299-308.

16. Gray SW, Park ER, Najita J, et al. Oncologists' and cancer patients' views on whole-exome sequencing and incidental findings: results from the CanSeq study. Genet Med. 2016;18:1011-9.

17. Kleiderman E, Knoppers BM, Fernandez CV, et al. Returning incidental findings from genetic research to children: views of parents of children affected by rare diseases. J Med Ethics. 2014;40:691-6.

18. Sanderson SC, Linderman MD, Suckiel SA, et al. Motivations, concerns and preferences of personal genome sequencing research participants: baseline findings from the HealthSeq project. Eur J Hum Genet. 2016;24:14-20.

19. Shahmirzadi L, Chao EC, Palmaer E, Parra MC, Tang S, Gonzalez KDF. Patient decisions for disclosure of secondary findings among the first 200 individuals undergoing clinical diagnostic exome sequencing. Genet Med. 2014;16:395-9.

20. Levenseller BL, Soucier DJ, Miller VA, et al. Stakeholders' opinions on the implementation of pediatric whole exome sequencing: implications for informed consent. J Genet Couns. 2014;23:552-65.

21. Payne K, Fargher EA, Roberts SA, et al. Valuing pharmacogenetic testing services: a comparison of patients' and health care professionals' preferences. Value Health. 2011;14:121-34.

22. Severin F, Hess W, Schmidtke J, et al. Value judgements for priority setting criteria in genetic testing: a discrete choice experiment. Health Policy. 2015;119:164-73.

23. Middleton A, Morley KI, Bragin E, et al. Attitudes of nearly 7000 health professionals, genomic researchers and publics toward the return of incidental results from sequencing research. Eur J Hum Genet. 2016;24:21-29.

24. Krabbenborg L, Vissers LELM, Schieving J, et al. Understanding the psychosocial effects of WES test results on parents of children with rare diseases. J Genet Couns. 2016;25:1207-14.

25. Sapp JC, Johnston JJ, Driscoll K, et al. Evaluation of recipients of positive and negative secondary findings evaluations in a hybrid CLIA-research sequencing pilot. Am J Hum Genet. 2018;103:358-66. 
26. Biesecker BB, Klein WMP, Lewis KL, et al. How do research participants perceive "uncertainty" in genome sequencing? Genet Med. 2014;16:977-980.

27. Han PKJ, Umstead KL, Bernhardt BA, et al. A taxonomy of medical uncertainties in clinical genome sequencing. Genet Med. 2017;19:918-25.

28. Newson AJ, Leonard SJ, Hall A, Gaff CL. Known unknowns: building an ethics of uncertainty into genomic medicine. BMC Med Genomics. 2016;9:57.

29. Patton, MQ. Qualitative evaluation checklist. Evaluation Checklists Project 2003: 1-13. available at: http://www.wmich.edu/eva lctr/checklists/qec.pdf

30. Miles MB, Huberman AM, Saldana J. Qualitative data analysis. Third edition, Sage, Arizona State University. 2014.

31. Regier DA, Friedman JM, Makela N, Ryan M, Marra CA. Valuing the benefit of diagnostic testing for genetic causes of idiopathic developmental disability: willingness to pay from families of affected children. Clin Genet. 2009;75:514-21.

32. Buchannan J, Wordsworth S, Schuh A. Patients' preferences for genomic diagnostic testing in chronic lymphocytic leukaemia: a discrete choice experiment. Patient. 2016;9:525-36.
33. Townsend A, Adam S, Birch PH, Lohn Z, Rousseau F, Friedman JM. "I want to know what's in Pandora's Box": comparing stakeholder perspectives on incidental findings in clinical whole genomic sequencing. Am J Med Genet A. 2012;158A:2519-25.

34. Marshall DA, Gonzales JM, MacDonald KV, Johnson F. Estimating preferences for complex health technologies: lessons learned and implications for personalized medicine. Value Health. 2017;20:32-39.

35. Regier DA, Peacock SJ, Pataky R, et al. Societal preferences for the return of incidental findings from clinical genomic sequencing: a discrete-choice experiment. CMAJ. 2015;187:E190-197.

36. Houdayer F, Gargiulo M, Frischmann M, et al. The psychological impact of cryptic chromosomal abnormalities diagnosis announcement. Eur J Med Genet. 2013;56:585-90.

37. Krabbenborg L, Schieving J, Kleefstra T, et al. Evaluating a counselling strategy for diagnostic WES in pediatric neurology: an exploration of parents' information and communication needs. Clin Genet. 2016;89:244-50.

38. Biesecker BB, Woolford SW, Klein WMP, et al. PUGS: a novel scale to assess perceptions of uncertainties in genome sequencing. Clin Genet. 2017;92:172-9.

\title{
Affiliations
}

\begin{abstract}
Aline Chassagne $e^{1,2,3}$ - Aurore Pélissier ${ }^{3,4}$ - Françoise Houdayer ${ }^{5}$ Elodie Cretin ${ }^{2,3}$ - Elodie Gautier ${ }^{6}$. Dominique Salvi $^{5}$ - Sarah Kidri ${ }^{5}$. Aurélie Godard ${ }^{1,2}$ - Christel Thauvin-Robinet ${ }^{3,6}$ - Alice Masurel ${ }^{6}$. Daphné Lehalle $\mathbb{1}^{6} \cdot$ Nolwenn Jean-Marçais $^{6} \cdot$ Julien Thevenon $\mathbb{1}^{6} \cdot$ Gaetan Lesca $^{5} \cdot$ Audrey Putoux $^{5}$. Marie-Pierre Cordier ${ }^{5}$. Sophie Dupuis-Girod ${ }^{5}$. Marianne Till ${ }^{5} \cdot$ Yannis Duffourd $^{3}$. Jean-Baptiste Rivière ${ }^{3}$. Lorraine Joly $^{6} \cdot$ Christine Juif $^{6}$ - Olivier Putois ${ }^{7} \cdot$ Pierre Ancet $^{8} \cdot$ Anne-Sophie Lapointe $^{9} \cdot$ Paulette Morin $^{9}$. Patrick Edery ${ }^{5}$ Massimiliano Rossi ${ }^{5} \cdot$ Damien Sanlaville $^{5}$. Sophie Béjean ${ }^{4}$. Christine Peyron ${ }^{4} \cdot$ Laurence Faivre $^{3,6}$
\end{abstract}

1 Laboratoire de Sociologie et d'Anthropologie (LaSA, EA3189), University of Burgundy Franche-Comté, Besançon, France

2 Clinical Investigation Center, Inserm 1431, CHRU Besançon, Besançon, France

3 FHU TRANSLAD et équipe GAD INSERM UMR 1231, University of Burgundy Franche-Comté, Dijon, France

4 Laboratoire d'Économie de Dijon (LEDI), EA7467, University of Burgundy Franche Comté, Dijon, France

5 Service de génétique clinique, Centre de Référence Anomalies du
Développement et Syndromes Malformatifs Centre Est- HCL, Lyon, France

6 Centre de Référence Anomalies of the Développement et Syndromes Malformatifs, Dijon University Hospital, Dijon, France

7 SuLiSoM EA 3071, Université of Strasbourg, Strasbourg, France

8 Centre Georges Chevrier, UMR 7366, University of Burgundy Franche-Comté Dijon, Dijon, France

9 Alliance Maladies Rares, Paris, France 